\title{
Urinary Interleukin-6 as biomarker for diagnosis of acute pyelonephritis in children
}

\author{
Ashraf Mohamed Abdelaal ${ }^{1}$, Abd AlHamed Salah Alden AlHamshary ${ }^{2}$, Osama Saad El Shaer ${ }^{3}$, \\ Amr Zakaria MohamedYounes ${ }^{2}$, Mustafa Mahmoud Khalil ${ }^{1}$ \\ 1- Urology department Banha university \\ 2- Pediatrics department Banha university \\ 3- Clinical Pathology department Banha university
}

\begin{abstract}
Introduction

Urinary Interleukin-6 (IL-6) a pleiotropic cytokine with pro-inflammatory and immune-regulatory functions is a key mediator of inflammation in children with Urinary tract infection (UTI).
\end{abstract}

Aim of the study

The aim of this study is to estimate the role of urinary IL-6 (UIL-6) in diagnosis of acute UTI in children and its usefulness in differentiation between upper urinary tract infection (UUTI) (pyelonephritis) and lower urinary tract infection (LUTI) (cystitis).

\section{Patients \& Methods}

This study conducted on a total 56 children divided into 36 patients suffering from UTI with mean age $4.3 \pm 3.1$ and 20 apparently healthy children age and sex matched with the cases. All patients were subjected to routine investigation and urine IL-6 assay.

\section{Results}

Urinary IL-6 was significantly higher in patients with UTI than control group, Sensitivity was $94.4 \%$, specificity of $92.1 \%$, positive predictive value was $85 \%$, negative predictive value was $97.2 \%$ and diagnostic accuracy was $92.8 \%$ and the best cut off value $>17$ $\mathrm{pg} / \mathrm{ml}$. Also Urinary IL-6 was significantly higher in acute pyelonephritis (APN) in comparison to lower UTI cases and there was a positive correlation between urinary IL-6 level and fever, CRP, and leukocyte count $[\mathrm{r}=0.623 \mathrm{P}=0.006, \mathrm{r}=0.816, \mathrm{P}<0.001$ and $\mathrm{r}$ $=0.688, \mathrm{P}<0.002$ respectively]

\section{Conclusion}

Urinary IL-6 level may considered as a reliable biochemical marker to determine the severity of renal injury in APN as well as outcome of pediatric patients

\section{Keywords}

Urinary tract infection, pyelonephritis, Interleukin 6 (IL-6), children

Running Title Urinary Interleukin 6 as biomarker of UTI

\section{Correspondence}

Ashraf Mohamed Abdelaal

Urology department Banha University

Email: ashrafm1970@gmail.com

Postal code: 11258

\author{
geget: The Journal of the Egyptian Society of Pediatric Nephrology and Transplantation (ESPNT) \\ geget https://geget.journals.ekb.eg/ \\ Published by ESPNT http://espnt.net/ \\ Cohosted by Egyptian Knowledge Bank https://www.ekb.eg
}




\section{Introduction}

Urinary tract infections (UTIs) still considered one of the most important diseases in children [1] that can lead to serious renal affection as permanent renal scarring [2]. High UTIs incidence reaches about $7.8 \%$ in children of 18 years old or below with urinary symptoms [3], this increases the risk of renal scarring and makes the management of this disease a critical item [4]. E coli is the most common cause of UTIs that is responsible for about $80 \%$ of UTIs in children [5], Other nonE.coli infections like Staphylococcus Saprophyticus, Enterococcus, Staphaureus and viruses like Adenovirus and Enterviruses and fungi like Candida species and Aspergillus species are uncommon causes for UTI $[5,6]$.

UTIs had many recorded serious complications: hypertension, renal scarring and renal failure. So accurate and early diagnosis is a must and to differentiate between upper and lower UTIs because of the serious complications that may result after upper UTI [7]. Antibiotics abuse like inappropriate use or overdose in children makes the clinical diagnosis of UTI inaccurate and confusing and makes UTI without clear symptoms of high ratio [8].UTI is responsible for $5 \%$ of all febrile episodes among infants. Upper UTIs (acute pyelonephritis) may result in renal scarring which increase the risk of secondary hypertension $[9,10]$.

Urinary IL-6 was first performed for diagnosis of acute pyelonephritis at university of Sumatera Uttara education centers and Haji Adam Malik hospital Medan [11], it is found in healthy children in small quantities but its levels increases significantly in kidney diseases [12]. In acute pyelonephritis, uro-epithelial cells secrete cytokines that introduce the inflammatory defense cells to the mucosa in response to bacterial invasion like IL-6 that can be detected in urine and serum [13].

\section{Aim of the study}

The aim of this study is to estimate the role of urinary IL-6 in diagnosis of acute urinary tract infection in children and its usefulness in differentiation between upper UTI (pyelonephritis) and lower UTI (cystitis).

\section{Patients and methods}

This study was conducted at the pediatric outpatient clinic at our university Hospital, Faculty of medicine; from June 2017 to January 2019, where total 56 children aged from 6 month to 11 years divided into 36 patients suffering from urinary tract infection for $1^{\text {st }}$ time with mean age $4.3 \pm 3.1$ and 20 apparently healthy children age and sex matched with the cases. Patients were classified into acute pyelonephritis

$(\mathrm{n}=18)$ and lower UTI $(\mathrm{n}=18)$ based on history, examination and investigation; Cystitis is suggested by features such as dysuria, frequency, urgency and lower abdominal discomfort while Pyelonephritis is suggested by systemic features such as fever, malaise, vomiting and loin tenderness [6].

All cases subjected to: Complete history taking, thorough physical examination and the following laboratory investigation: urine analysis, urine culture and sensitivity, complete blood count (CBC), C-reactive protein (CRP) and urine IL-6 assay (by ELISA technique). Children who had been treated with antibacterial agents within seven days before the admission, and children with known urologic malformation, associated infection, and neurologic disorders were excluded.

\section{Statistical analysis}

All statistical calculations were done using computer programs SPSS (Statistical Package for the Social Science; SPSS Inc., Chicago, IL, USA version 20 for Microsoft Windows).

Analysis of Variance (ANOVA) is a statistical method used to test differences between two or more means. A Bonferroni test is a type of multiple comparison test used in statistical analysis.

\section{Results}

E coli was the most common isolated organism in urine culture followed by Staph, Klebsiella then proteus (table1). We found a significant higher levels of both TLC and CRP levels in UUTI group in comparison to LUTI group and control group (table 2). There was a highly significant increase in IL6 among studied group in comparison to control group, also significant difference between UUTI group \& LUTI group (table 3 ).

At a cut off value $\geq 17.7(\mathrm{ng} / \mathrm{ml})$. IL6 Sensitivity for early diagnosis of UTI was $94.4 \%$ with specificity $92.1 \%$, positive predictive value (PPV) $85 \%$, negative predictive value (NPV) 97.2\%, AUC: 0.972 and highly sensitive correlation with UTI (P value $<0.001$ ), On the other hand figure 1 , at Cut off value $\geq 18$ CRP sensitivity for early diagnosis of UTI was $94.4 \%$ with specificity $78.9 \%,(\mathrm{PPV})$ of $68 \%$, NPV of $96.7 \%$, AUC : 0.944 and high positive significant correlation with urinary tract infection ( $p$ value $<0.001$ ), at Cut off value $\geq 14.1$ Total Leucocytic count (TLC) sensitivity for early diagnosis of UTI was $88.9 \%$ with specificity $84.2 \%$, (PPV) of $72.7 \%$, NPV of 94.1\%, AUC: 0.946 and high positive significant correlation with urinary tract infection ( $p$ value $<0.001$ ) (table 4). Our results showed positive correlation between IL6, fever, TLC and CRP (table 5).

Table 1 Urine culture results among patients group

\begin{tabular}{|c|c|c|}
\hline Culture results & No $(\mathbf{n = 3 6 )}$ & \% (100.0) \\
\hline E coli & 18 & 50.0 \\
\hline Pseudomonas & 2 & 5.6 \\
\hline Staph & 10 & 27.8 \\
\hline Klebsiella & 4 & 11.1 \\
\hline Proteus & 1 & 2.8 \\
\hline Acinetobacter & 1 & \\
\hline
\end{tabular}


Table 2 Comparing the studied groups regarding TLC and CRP

\begin{tabular}{|c|c|c|c|c|c|c|c|c|c|}
\hline \multirow[t]{2}{*}{ Group } & & \multicolumn{2}{|c|}{ TLC } & \multirow{2}{*}{$\begin{array}{c}\text { ANOVA } \\
\text { test }\end{array}$} & \multirow[t]{2}{*}{$\mathbf{P}$} & \multicolumn{2}{|c|}{ CRP } & \multirow[t]{2}{*}{ ANOVA } & \multirow[t]{2}{*}{$\mathbf{P}$} \\
\hline & & Mean \pm SD & Range & & & Mean \pm SD & Range & & \\
\hline UUTI & 18 & $19.1 \pm 5.8$ & $13.3-24.9$ & \multirow[t]{3}{*}{141} & \multirow{3}{*}{$\begin{array}{c}<0.001 \\
(\mathrm{HS})\end{array}$} & $124 \pm 30$ & $94-154.2$ & \multirow[t]{3}{*}{87.3} & \multirow{3}{*}{$\begin{array}{c}<0.001 \\
(\mathrm{HS})\end{array}$} \\
\hline LUTI & 18 & $9 \pm 4.1$ & $5.1-13.1$ & & & $16.1 \pm 3.8$ & $13-19.1$ & & \\
\hline Controls & 20 & $6.9 \pm 2.5$ & $4.4-9.4$ & & & $2.7 \pm 2.3$ & $0.4-5$ & & \\
\hline
\end{tabular}

Table 3 Comparing the studied groups regarding urinary IL-6

\begin{tabular}{|c|c|c|c|c|c|c|c|}
\hline \multirow{2}{*}{ Group } & & \multicolumn{2}{|c|}{ Urinary IL-6 (Pg/ml) } & \multirow{2}{*}{$\begin{array}{c}\text { ANOVA } \\
\text { test }\end{array}$} & \multirow{2}{*}{$\mathbf{P}$} & \multirow{2}{*}{$\begin{array}{l}\text { Bonferroni test for } \\
\text { sig. pairs }\end{array}$} & \multirow{2}{*}{$\mathbf{P}$} \\
\hline & & Mean \pm SD & Range & & & & \\
\hline UUTI & 18 & $23.1 \pm 3.74$ & $18.2-29.4$ & \multirow{3}{*}{132.7} & \multirow{3}{*}{$\begin{array}{c}<0.001 \\
(\mathrm{HS})\end{array}$} & \multirow{3}{*}{$\begin{array}{c}\text { UUTI } \neq \text { LUTI } \\
\text { UUTI } \neq \text { Controls } \\
\text { LUTI } \neq \text { Controls }\end{array}$} & \multirow{3}{*}{$\begin{array}{c}<0.001(\mathrm{HS}) \\
<0.001(\mathrm{HS}) \\
0.009\end{array}$} \\
\hline LUTI & 18 & $14.8 \pm 1.91$ & $12-18.7$ & & & & \\
\hline Controls & 20 & $8.1 \pm 2.56$ & $3.3-10.6$ & & & & \\
\hline
\end{tabular}

Table 4 Validity and predictively of Urinary IL-6, TLC and CRP in prediction of patients with UUTI

\begin{tabular}{|c|c|c|c|c|c|c|c|c|c|}
\hline Marker & $\begin{array}{c}\text { Cutoff } \\
\text { Value }\end{array}$ & $\begin{array}{c}\text { Sens } \\
\text { \% }\end{array}$ & Speci \% & PPV \% & $\begin{array}{c}\text { NPV } \\
\text { \% }\end{array}$ & Acc $\%$ & AUC & 95 \% CI & P \\
\hline UIL-6 & $\geq 17.7$ & $94.4 \%$ & $92.1 \%$ & $85 \%$ & $97.2 \%$ & $92.8 \%$ & 0.972 & $0.93-1.0$ & $<0.001(\mathrm{HS})$ \\
\hline CRP & $\geq 18$ & $94.4 \%$ & $78.9 \%$ & $68 \%$ & $96.7 \%$ & $83.9 \%$ & 0.944 & $0.89-1.0$ & $<0.001(\mathrm{HS})$ \\
\hline TLC & $\geq 14.1$ & $88.9 \%$ & $84.2 \%$ & $72.7 \%$ & $94.1 \%$ & $85.7 \%$ & 0.946 & $0.89-1.0$ & $<0.001(\mathrm{HS})$ \\
\hline
\end{tabular}

Sens= sensitivity speci= specificity

$\mathrm{PPV}=$ Positive Predictive Value,

$\mathrm{AUC}=$ Area Under Curve
NPV= Negative Predictive Value,

$\mathrm{CI}=$ Confidence Interval

Table 5 Correlation between UIL-6 and the studied variables among UUTI group

\begin{tabular}{|c|c|c|}
\hline \multirow{2}{*}{ With } & \multicolumn{2}{|c|}{ U IL-6 ( pg/ml ) } \\
\cline { 2 - 3 } & Rho & UUTI group (n = 18) \\
\cline { 2 - 3 } Age & 0.042 & 0.86 \\
\hline Degree of fever* & 0.623 & $0.006(\mathrm{~S})$ \\
\hline TLC & 0.688 & $0.002(\mathrm{~S})$ \\
\hline CRP & 0.816 & $<0.001(\mathrm{HS})$ \\
\hline
\end{tabular}

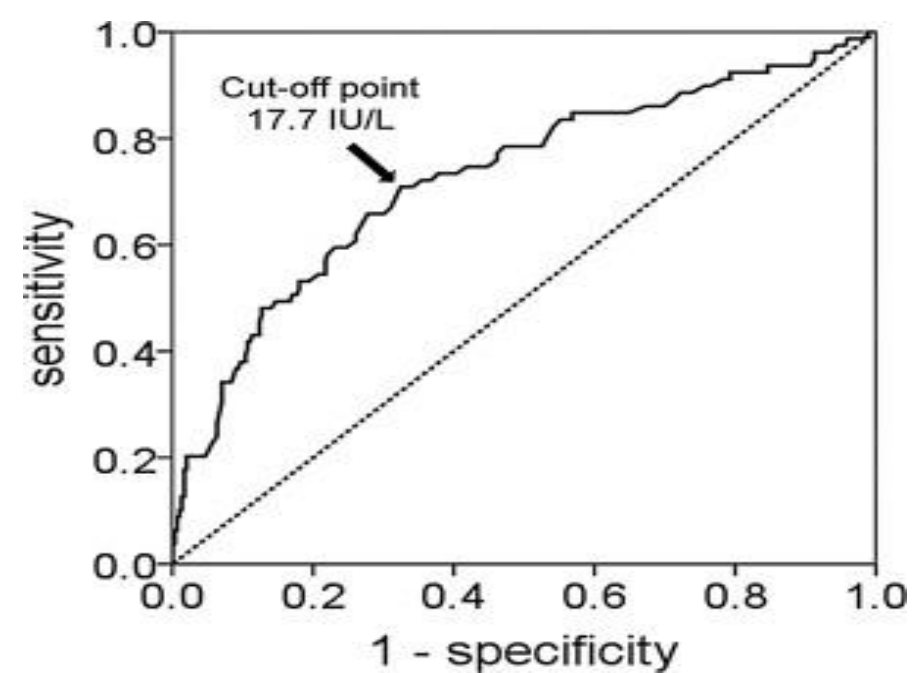

Figure 1 ROC curve presenting cut off level of uIL6 $(17.7 \mathrm{pg} / \mathrm{ml})$ 


\section{Discussion}

Urine analysis and culture and sensitivity is the first step for diagnosis of UTI ,also there are many UTI markers for its detection and diagnosis like leukocyte Esterase ,ESR, C reactive protein ,tumor necrosis factor ,total leucocyte count and interleukin $6[9,10]$. This study was conducted at the pediatric outpatient clinic at our university Hospital, Faculty of medicine, from June 2017 to January 2019, a total of 56 children aged from 6 months to 11 years divided into 36 patients suffering from urinary tract infection with mean age $4.3 \pm 3.1$ and 20 apparently healthy age- and sex- matched children as a control group were included in the study. All patients were subjected to laboratory investigations; urine analysis, urine culture and sensitivity, complete blood count (CBC), C-reactive protein (CRP) and urine IL-6 assay (by ELISA technique).

Our study proved that there was highly significant increase in UTI patients than controls as regard to TLC; this is in agreement with Shah G. and Upadhyay J. who stated that there is increase in leukocytosis with acute pyelonephritis [14] but our results disagree with Manucha $\mathrm{V}$, et al who reported that the total leukocytic count is of little clinical benefit in the diagnosis of UTI because of the wide variation in values and the overlapping between normal and abnormal values [15].

Our study showed that there was highly significant increase in CRP in UTI patients than controls this came in agreement with Shah G. and Upadhyay J. who reported elevation in CRP but it is nonspecific marker of bacterial infection [14] also Shah G. and Upadhyay $\mathrm{J}$. report that microscopic WBCs in urine increase in UTI as found in our study.

As regard urine culture; There was highly significant positive cultures in UTI patients than controls.We found that E.coli organism was the most common isolated $(50 \%)$ of cases and these results matched with Rai, G. K., et al who found E. coli to be the most common cause of UTI, followed by Staphylococcus aureus, klebsiella, pseudomonas and proteus [16]. But Adeleke S.I. and Asani M.O. found that Staph. aureus was the commonest organism $(67.9 \%)$ of isolates, followed by Klebsiella $(17.9 \%)$ then Pseudomonas (14.2\%) [17]; this can be explained by the geographical difference as regard locality of the study.

Sheu, J. N., et al reported that sensitivity and specificity in differentiating acute pyelonephritis from lower UTI were 74\% and $72 \%$, respectively, for $\mathrm{WBC}$ and $93 \%$ and $81 \%$, respectively [18] as shown in our study the mean level of total leucocytic count (TLC) \& C-reactive protein (CRP) were significantly higher in acute pyelonephritis than lower UTI [P value $<0,001]$ (table 2). Also other researches had studied the level of inflammatory markers in patients with UTI. Lin D. S., et al found that CRP and ESR levels were imperfect tools in diagnosis of UTI, and the sensitivity of these laboratory parameters was relatively low, while TLC was a significantly better predictor of UTI in febrile infants [19], on the other hand Rodríguez L. M., et al showed that CRP is considered a valuable test in diagnosis of febrile UTI (APN) which showed high sensitivity $83.3 \%$ than uIL-6 which was $77.8 \%$ [20].

Gürgöze M. K., et al performed a study on 76 children with UTI showed that inflammatory markers such as CRP, ESR, TLC count, procalcitonin, uIL- 6 , and IL- $1 \beta$ in patients with acute pyelonephritis were significantly higher than lower UTI [21], and Krzemień G., et al study revealed elevated inflammatory markers in all cases with febrile UTI (elevated ESR and CRP in
$100 \%$ of patients, and leukocytosis in $90 \%$ ), compared to 19 children with lower UTI (elevated ESR in $30 \%$ of the patients, CRP in $5.5 \%$ of the patients, and TLC in $69.6 \%$ of the patients); where the mean values of ESR, CRP and TLC were significantly higher in pyelonephritis than lower UTI [22].

In our study, we found that urine levels of IL-6 were significantly high in all patients with pyelonephritis compared to the control group as the diagnostic sensitivity was $94.4 \%$, specificity was $92.1 \%$ and urinary interleukin-6 level $>17 \mathrm{pg} / \mathrm{ml}$ is the best cut off value for early recognition of acute pyelonephritis. Also our study proved that urinary IL-6 levels increased significantly more in acute pyelonephritis cases than in lower UTI; this is in a agreement with with Rodríguez L. M., et al who showed that a concentration $>15 \mathrm{pg} / \mathrm{ml}$ is a highly reliable marker of APN. Also we found that urinary interleukin6 was useful in distinguishing between upper and lower UTI in children agreed with Tramma D, et al who found that IL-6 production in UTI is a useful biomarker In children [23]. Similarly Jantausch B. A., et al found that both serum and urine IL-6 are useful diagnostic tools for early recognition of acute urinary tract infection in febrile children, and also it can be used for differentiation between upper and lower UTI [24]. Also Sheu, J. N., and his associates found that urine level of IL-6 was significantly increased in children with acute pyelonephritis than in lower UTI and found also both serum and urine levels of IL6 have high sensitivity (81-88\%) and specificity of (78-83\%) for the diagnosis of acute pyelonephritis and make accurate differentiation from lower UTI (18). Gürgöze M. K. and his colleagues came in similar results as they found that serum IL-6 levels rise significantly in children with acute pyelonephritis, and it had sensitivity $88 \%$ and specificity $74 \%$ [21]. On the contrary a study done by Mahyar A., et al showed that sensitivity and specificity of IL-6 and IL-8 are less than acute phase reactants such as CRP and reported that these cytokines are not reliable markers for differentiating acute pyelonephritis from lower UTI [25].

In our study, among cases, there were correlations between urine IL-6 and inflammatory markers and temperature. There were highly statistically significant positive correlation between urinary IL-6 and TLC, CRP and temperature and this was proved by Sheu, J. N., and his associates who found that in children with acute pyelonephritis uIL-6 was significantly correlated with fever and CRP but not correlate with WBC (18). The positive correlation of serum and urinary IL-6 levels with systemic inflammatory markers (such as fever, CRP and TLC); is consistent with the hypothesis that the release of IL- 6 from the urinary tract into the circulation leads to the induction of these systemic host responses, and large amounts of IL-6 production in tissues within and outside the urinary tract contributes to the higher serum IL-6 levels. These findings suggest that IL-6 is a key mediator of inflammation in children with acute pyelonephritis [18]. On the contrary Benson M., et al. compare serum and urine IL-6 levels and inflammatory markers in children with UTI and found a correlation of urine IL-6 levels with local inflammatory markers including proteinuria, hematuria and leucocyturia. In that study, there were no correlations of serum and urine IL-6 levels with fever or CRP [26]. In studies concerned with bacterial infections results may differ from on study to others as it may depend on geographical infection type predictions and laboratory measurements methods. 


\section{Conclusion}

We concluded that, urinary IL-6 level may serve as a reliable diagnostic tool for the early identification of acute urinary tract infection in febrile children (diagnostic accuracy is 94.4\%) and we confirmed the usefulness of determining urinary IL- 6 as a biochemical marker is to determine the severity of renal injury in APN as well as outcome of patients. In spite of being an expensive test, yet its benefits may exceed its cost as it make the use of more aggressive diagnostic tests unnecessary.

\section{References}

1. Beetz R. May we go on with antibacterial prophylaxis for urinary tract infections? Pediatr Nephrol. 2006; 21:5-13.

2. Dinkel E, Orth S, Dittrich M, Schulte-Wissermann H. Renal sonography in the differentiation of upper from lower urinary tract infection. AJR Am J Roentgenol. 1986; 146:775-80.

3. Shaikh N., Morone N. \& Bost J. (2008). Prevalence of Urinary Tract Infection in Childhood: A Meta-Analysis. Pediatr Infect Dis J. 2008; 27:302.

4. Shaikh N., Craig J., Rovers M. et al. Identification of children and adolescents at risk for renal scarring after a first urinary tract infection: a meta-analysis with individual patient data JAMA Pediatr. 2014;168(10):893-900.

5. Edlin RS, S. D. (2013). Antibiotic resistance patterns of outpatient pediatric urinayr tract infections. J Urol. 2013; 190:222.

6. Wald E. Cystitis and pyelonephritis. In H. G. Cherry JD, Feigin and Cherry's Textbook of Pediatric Infectious Diseases. 2014; 7th ed (p. p.535.). Philadelphia: Elsevier Saunders.

7. Sastre JBL, Aparicio AR, Cotallo GDC, Colomer BF, Hernandez $\mathrm{MC}$ Urinary tract infection in the newborn: clinical and radio imaging studies. Pediatr Nephrol. 2014; 22(10): 1735-1741.

8. Phillips CD, Adepoju O, Stone $\mathrm{N}$ et al. Asymptomatic bacteriuria, antibiotic use, and suspected urinary tract infections in four nursing homes. BMC Geriatr. 2012; 12: 73.

9. Oke Rina R, Nezman N, Rafita R, Nelly R, Rosmayanti S $S$, et al. The Accuracy of Interleukin-6 Urine Compared to Urine 002 Culture to Diagnose Pyelonephritis in Neonates. JOJ uro \& nephron. 2017; 1(5): 555574.

10. Hoberman A, Charron M, Hickey RW, Baskin M, Kearney DH, Wald ER. Imaging studies after a first febrile urinary tract infection in young children. N Engl J Med. 2003; 348:195-202.

11. Godaly G, Otto G, Burdick MD, Strieter RM, Svanborg C. Fimbrial. Lectins influence the chemokine repertoire in the urinary tract mucosa. Kidney Int. 2007; 71:778-86.

12. Sundvall PD, Elm M, Ulleryd $P$ et al. Interleukin-6 concentrations in the urine and dipstick analyses were related to bacteriuria but not symptoms in the elderly: a cross sectional study of 421 nursing home residents. BMC Geriatr. 2014; 14: 88.

13. Pardede SO, Tambunan T, Alatas H, Trihono PP, Hidayati EL. Konsensus infeksi saluran kemih pada anak. In:
Pardede SO, et al. (Eds.), Badan Penerbit Ikatan Dokter Anak Indonesia. 2011; Indonesia, pp. 1-7

14. Shah G. and Upadhyay J. Controversies in the diagnosis and management of urinary tract infections in children. Paediatric Drugs. 2005; 7:339-346

15. Manucha V., Rusia U and Sikka M, et al. Utility of hematological parameters and C-reactive protein in the detection of neonatal sepsis. J Pediatr Child Health. 2008; 38(5): 459-564.

16. Rai, G. K., Upreti, H. C., Rai, S. K., Shah, K. P., \& Shrestha, R. M. Causative agents of urinary tract infections in children and their antibiotic sensitivity pattern: a hospital based study. 2008.

17. Adeleke S.I. and Asani M.O. Urinary tract infection in children with nephrotic syndrome in Kano, Nigeria. Ann Afr Med. 2009; 8: 38-41.

18. Sheu, J. N., Chen, M. C., Lue, K. H., Cheng, S. L., Lee, I. C., Chen, S. M., \& Tsay, G. J. Serum and urine levels of interleukin- 6 and interleukin- 8 in children with acute pyelonephritis. Cytokine. 2006; 36(5-6), 276-282.

19. Lin D. S., Huang F. Y., Chiu N. C., et al. Comparison of hemocytometer leukocyte counts and standard urinalyses for predicting urinary tract infections in febrile infants. The Pediatric infectious disease journal. 2000; 19(3), 223-227.

20. Rodríguez L. M., Robles B., Marugán J. M., et al. Urinary interleukin- 6 is useful in distinguishing between upper and lower urinary tract infections. Pediatric Nephrology. 2008; 23(3), 429-433.

21. Gürgöze M. K., Akarsu S., Yilmaz E.,et al. Proinflammatory cytokines and procalcitonin in children with acute pyelonephritis. Pediatric Nephrology. 2005; 20(10), 1445-1448.

22. Krzemień G., Roszkowska-Blaim M., Kostro, et al.. Urinary levels of interleukin-6 and interleukin-8 in children with urinary tract infections to age 2. Medical Science Monitor. 2004; 10(11), CR593-CR597.

23. Tramma D., Hatzistylianou M., Gerasimou G., et al. Interleukin-6 and interleukin-8 levels in the urine of children with renal scarring. Pediatric Nephrology. 2012; 27(9), 1525-1530.

24. Jantausch B. A., O’Donnell R. \& Wiedermann B. L. Urinary interleukin-6 and interleukin-8 in children with urinary tract infection. Pediatric Nephrology. 2000; 15(34), 236-240.

25. Mahyar A., Ayazi P., Maleki M. R., et al. Serum levels of interleukin-6 and interleukin-8 as diagnostic markers of acute pyelonephritis in children. Korean journal of pediatrics. 2013; 56(5), 218-223.

26. Benson M., Jodal U., Andreasson A., et al. Interleukin 6 response to urinary tract infection in childhood. The Pediatric infectious disease journal. 1994; 13(7), 612-616. 


\section{Statements}

\section{Ethical approval}

This study protocol and the consents were approved and deemed sufficient by the Ethical Committee of Banha University and informed written consent was obtained in every case from their legal guardians.

\section{Consent for publication}

"Not applicable"

Availability of data and material

"Not applicable

\section{Conflict of interest}

We declare there is no conflict of interest.

\section{Funding}

We declare that this research work did not revise any fund

Acknowledgements

Authors thank Mr. Mohamed Samir statistician for his

valuable support in preparing our results 